\title{
Rapid Prototyping as an Experimentation Method of Designing Tools to Improve the Quality and Variety of Stitch-Resist Dyed Motifs
}

\author{
Bintan Titisari ${ }^{1 *}$, Slamet Riyadi ${ }^{2}$
}

\author{
${ }^{1}$ Institut Teknologi Bandung, Indonesia \\ ${ }^{2}$ Institut Teknologi Bandung, Indonesia \\ "Corresponding author.Email: bintan.titisari@office.itb.ac.id
}

\begin{abstract}
This paper discusses initial findings from an ongoing research project that designing a tool to improve the quality and variety of stitch-resist dyed motifs in Indonesia. Stitch-resist dyeing technique has been used to produce Indonesian traditional cloths, such as Jumputan cloth, Tritik cloth, Pelangi cloth and Sasirangan cloth. In the past 30 years, the use of this technique has been transformed from producing an individual artwork to mass craft production. Although the transformation provides economic benefits for the craft makers, an issue had been raised about the decreasing motif quality and the increasing number of defect patterns. Designing a stopper tool using the rapid prototyping method with biodegradable materials can be one of the alternatives to improve the quality and variety of motifs. The tool would increase the resist area which has been done manually by knotting the sewing thread after it is pulled. The resist area prevents the dye liquid from entering the area which eventually forms a pattern at the end of this process. The method used in this study used an experimentation approach with rapid prototyping method using Fused Deposition Modeling (FDM) based 3D printer. The biodegradable material focuses on the use of Polylactic Acid (PLA), made from corn with a low environmental impact. At this stage, the research is still an ongoing process and the validating stage had not been conducted, although the final design of the prototyping tool had been done. The prototype is expected to solve the production issue of the stitch-resist dyeing technique by producing more precise and consistent pressure compared to manual knots without changing the existent culture among Indonesian craft makers. The further works are to analyze the effect of using the tool on the stitch-resist dyeing process and how it will affect the resultant motifs
\end{abstract}

Keywords: stitch-resist dyeing, textile patterns, appropriate technology, rapid prototyping, sustainable material

\section{INTRODUCTION}

This paper presents and discusses initial findings of an ongoing research project that uses a rapid prototyping method to design a biodegradable materials-based tool for stitch-resist dyeing technique. In a larger scheme, this research is a fractional part of "The development of a good practice for the Indonesian stitch-resist dyeing practices which culturally and environmentally significant for the craft makers". This grant research starts in 2016 and plans to continue until 2027. Up until now, the research had published two publications [1] [2]. The research background pertains heavily to the issue of globalization impacts on the craft practices [3], not only in Indonesia but also in other countries in South Asia and South-East Asia in the past decades [4] [5] [6] [7]. The modernization has shifted the worldwide society into consumers of capitalism and industrialization [3], which adversely affects the work of traditional craft people [6]. Many craft people are expected to continuously evolve and transform to fulfil the modern society's needs, forcing their practices to shift from material culture into a commodity [8], from traditional to industrial production [7]. In a long 
term, the imprudent adaptation of modern technology will not be culturally and environmentally sustained.

The Indonesian textile craft makers face a similar situation. The emergence of creative industries in the past 30 years and the recognition of batik cloth by UNESCO in 2009 [9] had brought a high popularity to the traditional cloths. The Indonesian government encourages Indonesian employees to be dressed in office wear made from Batik and other Indonesian traditional fabrics every Thursday and Friday [10] which affects many textile craft practices in Indonesia to produce traditional cloth in large quantities, some of them are the craft makers of Jumputan and Tritik cloths in Yogyakarta, Pelangi cloths and Sasirangan cloths which employ the stitch-resist dyeing technique [2]. They must shift their practices from producing individual traditional clothes into a large sale and uniform cloth [2]. The shifted condition provides economic benefits for some stitch-resist dyeing crafts makers and consequently raises several issues. Some of the issues are the motif quality has decreased and the failure rate in manufacturing stitch-resist dyed motifs on the fabric has increased due to the urgency to create a large quantity of cloths in relatively short time [2].

The most significant part from the stitch-resist dyeing technique is the process of knotting the sewing thread after being pulled because it forms a closed area so that the dye cannot enter the area and form a motif. The knotting process is done manually by the craft makers. One of the suggested revitalization strategies in improving the quality and variety of motifs is to design a tool that is useful for increasing strength during the knotting process [2]. The tool should be simple, affordably low-cost, and environmentally friendly, so it can be used individually by the craft makers without altering the existing working culture [1]. Therefore, this research selects to experiment with biodegradable materials, Polylactic Acid (PLA) made from corn which has a low environmental impact and produced it with a rapid prototyping method on a laboratory scale.

\section{STITCH-RESIST DYEING PRACTICES IN INDONESIA}

The stitch-resist dyeing process has been widely used among Indonesian craft makers. However, the depth of understanding of this technique is mostly related to Pelangi cloths in Palembang, Jumputan and Tritik cloths in Yogyakarta, and Sasirangan cloths in Banjarmasin [11] [12] [13] [14] [2]. Based on a survey in 2016-2017, the craft makers in those three locations produce stitch-resist dyed fabrics for retail and corporate wear in relatively large quantities (approx. 500-1000 cloths per month per craft maker) with uniformity in design [2]. The practices form as craft industries instead of individual artisans, creating their own supply chain within the enterprise or cooperative scheme [2].

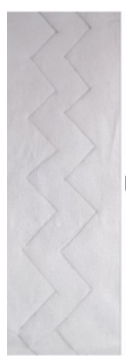

(a)

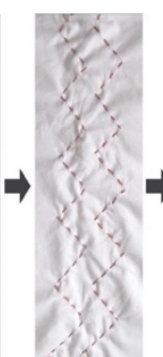

(b)

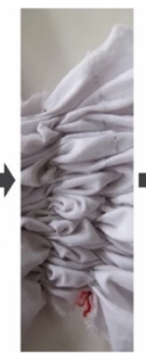

(c)

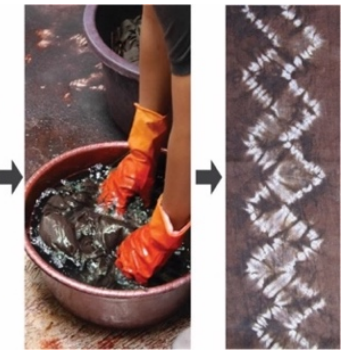

(d)

(e)
Figure 1. A simple sequence of the stitch-resist dyeing process: (a) draw the line on fabric; (b) apply running stitches; (c) pull and knot the sewing threads; (d) color or dye the fabric; (e) resultant pattern after cutting the knot.

The stitch-resist dyeing technique defines as a method in creating a textile pattern by applying running stitches on the woven fabric, then pulling the sewing thread and knotted at the end to protect that area from dyeing penetration [15] [16]. Some pleats are formed after being pulled in that protected area which later forms a motif. A simple sequence on creating the stitch-resist dyeing pattern is described in Figure 1. As shown in Figure 1, the knotting process (step c) and the knot opening process (step e) plays an essential part in defining how the pattern is formed after the dyeing process; thus, every maker must knot it tightly then cut the knot carefully with a scissor or cutter. The Indonesian craft makers conduct the process manually with high craftsmanship skills. Still, some makers give less attention to this process due to time efficiency, causing some low-quality patterns or sometimes defect patterns [2].

To overcome the issues mentioned above, Titisari [2] suggested an appropriate technology for the Indonesian stitch-resist dyeing. The manual knotting process can be replaced by a stopper tool which expectedly produces more precise and consistent pressure compared to manual knots and avoids a torn fabric when cutting the knot [2]. Although, the tool must be able to accommodate the complexity of the pattern in one fabric and be ergonomic for its users. In addition, the proposed tool also opens opportunities to explore more variety motifs from the stitch-resist dyeing technique by performing repeat closing and coloring processes [2]. A sequence 
comparison between the traditional method and the modification method with a stopper tool is illustrated in Figure 2.

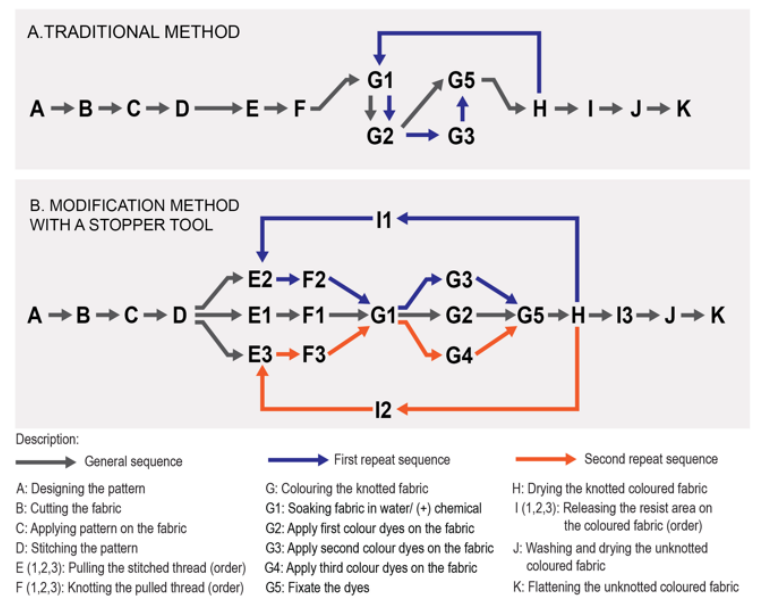

Figure 2. A comparison between: (A) a sequence of stitch-resist dyeing traditional method and (B) a modified sequence of stitch-resist dyeing with the stopper tool [2].

\section{RAPID PROTOTYPING METHOD BASED ON BIODEGRADABLE MATERIALS}

This study used an experimentation approach with rapid prototyping method using Fuse Deposition Modeling (FDM) based 3D printer. The tool prototype produced from this research is expected to solve the production issue of the stitch-resist dyeing technique and fulfil the principles of sustainable design by covering environmental, economic, social, and cultural aspects. The material consideration for this prototype tool refers to the principles of life cycle design (LCD), such as minimizing material consumption, using non-toxic and harmless materials, using renewable (biodegradable) and biocompatible materials, and extending the material life [17]. However, the material used for this tool must have a durability that can accommodate the coloring process that requires high temperatures.

For this study, the prototype utilizes Polylactic Acid (PLA) as the main material which is a biodegradable material and has low environmental impact [18] [19]. Polylactic acid (PLA) is the most common starch-based biopolymers, which are derived from $100 \%$ annually renewable crops such as corn, rice, wheat, and sugar beet [20] [21]. Currently, PLA based on corn starch is considered as sustainable materials from a resource utilisation point of view compared to oil-based materials [18] [20].
Compared to Polyethylene Terephthalate (PET) and Poly Styrene (PS), the corn based Polylatic Acid (PLA) is considered as a suitable material considering the lowest environmental impact in terms of the end-life scenario [19]. PLA can be $100 \%$ recyclable and/or compostable, although the energy used for recycling is less than composting [19] [22]. Therefore, the experimentation applies the rapid prototyping method using 3D printing with the FDM technique using PLA material (Figure 3 and Figure 4).

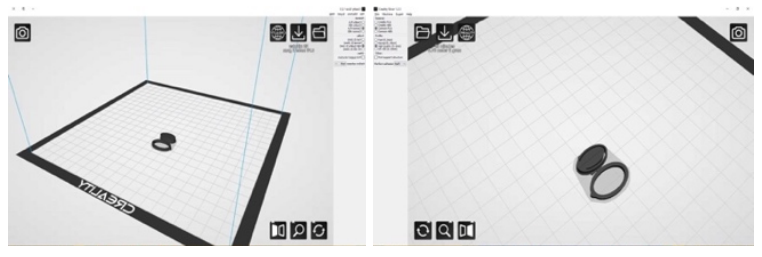

Figure 3. The 3-Dimensional image of designing process of the prototype
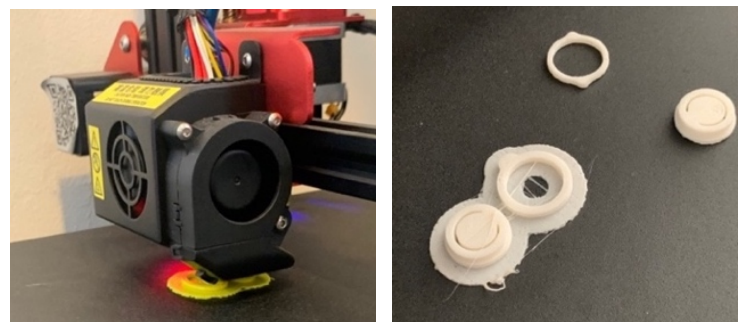

Figure 4. Rapid prototyping process using Fuse Deposition Modelling (FDM)

\section{FINDINGS AND DISCUSSION}

The exploration stage in developing the tool is done by designing several alternative designs by applying a simple clamping mechanism with the aim to precisely hold the thread used to apply the dyeing technique. After several clamping mechanisms developed from the experimentation process have been made, a simple test is carried out to find a design with a clamping mechanism that is considered the most consistent and precise that can outperform conventional techniques. After several test, the form of the selected prototype was narrowed down into two alternatives (Figure 5).

Two designs resulted from the exploration are developed by considering the nature of the PLA material which are flexible and soft. To produce a consistent clamping mechanism from the material, a design that capable of stopping the clamping mechanism is required so that the clamped sewing thread does not shift easily due to the flexible PLA material. Therefore, the two alternative designs should consist of two components, namely the first 
component which is for clamping the sewing thread and the second component which is the locking part. The difference lies in the opening mechanism.
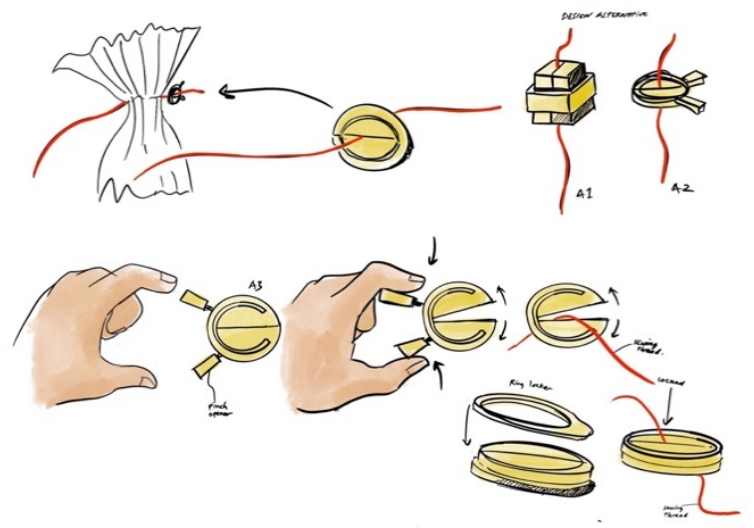

Figure 5. Exploring several designs of the prototyping tool

The first alternative design (Figure 6a) uses an opening lever so that the two clamping parts do not detach from each other, while the second design
(Figure 6b) does not have an opening lever so that the two clamping parts are separate parts. From both design alternatives, an analysis was done in term of their usability and the resultant pattern possibility. The strengths and weaknesses of both designs are described in the table below (Table 1). Apart from the existing weaknesses, the two prototype designs can hold the sewing thread position very well and have more efficient process compared to the conventional knotting technique. Thus, the motif quality that is resulted from these tools is expected to be more precise and more consistent.

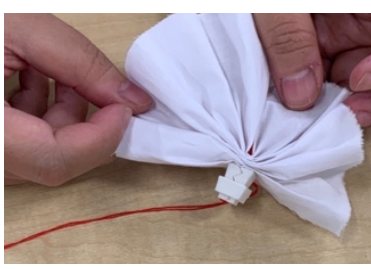

(a)

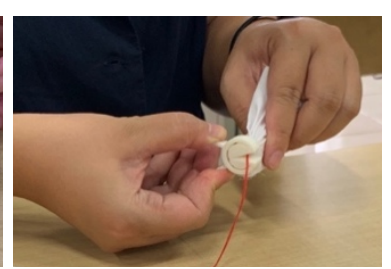

(b)
Figure 6. Testing the design alternatives: (a) Design 1 and (b) Design 2

Table 1. The design analysis of initial prototyping tool for the stitch resist dyeing

\begin{tabular}{|l|l|l|}
\hline \multicolumn{1}{|c|}{ Design } & \multicolumn{1}{|c|}{ Strength } & \multicolumn{1}{|c|}{ Weakness } \\
\hline Design 1 & $\begin{array}{l}\text { The tool has two parts: the clamping and the lock part. } \\
\text { Both parts hold the sewing thread very tight. } \\
\text { The cross-sectional area of the clamping device is } \\
\text { smaller than the design 2, so it will create a small } \\
\text { covering area at the end of sewing thread. In other } \\
\text { words, it is assumed that there might be an additional } \\
\text { motif from the use of this tool. }\end{array}$ & $\begin{array}{l}\text { The clamping tool will be detached when it is not used, } \\
\text { so there is a possibility that both parts of the clamp will } \\
\text { be lost during the application because there is no } \\
\text { connecting lever that connects the two parts of the } \\
\text { clamp. }\end{array}$ \\
\hline Design 2 & $\begin{array}{l}\text { The tool has one part with a locking system at the edge. } \\
\text { The tool holds the sewing thread very tight. } \\
\text { The clamping tool has a connecting lever that will keep } \\
\text { the two clamping halves attached. }\end{array}$ & $\begin{array}{l}\text { The cross-sectional area of the clamping device is } \\
\text { bigger than the design 1, so it is presumably will create } \\
\text { a large covering area at the end of sewing thread. In } \\
\text { other words, there might be an additional motif from the } \\
\text { use of this tool. }\end{array}$ \\
\hline
\end{tabular}

Considering the strength and weakness from both prototype designs, the refinement had been made to finalize the prototype design (Figure 7). The final design is considered to be more ergonomic and use less material in terms of structure. However, this research is still ongoing so the final prototype designs still must be tested in the coloring process. There will be two points that will be analyzed in testing the prototype in the coloring process: (1) the motifs generated by using these tools compared to the conventional knotting technique and (2) the user experience of the tools (efficiency and effectiveness of the process)
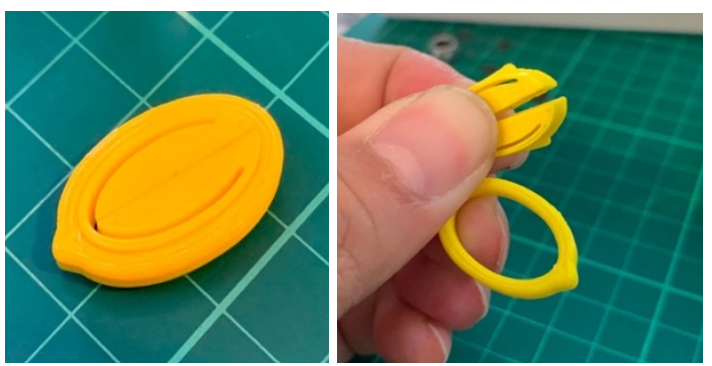

Figure 7. Final design of the prototyping tool 


\section{CONCLUSION AND FURTHER WORKS}

With the refinement of the final design of the tool, this research opens the opportunity to be able to proceed to field testing with real users and compare the results with conventional knotting methods. The further works is to analyze the effect of using the tool on the stitch-resist dyeing process and how it will affect the resultant motifs. The analysis will be focused on from the quality of pattern resulted by this tool and from the user perception about this tool.

\section{ACKNOWLEDGMENTS}

This research is fully funded by The Faculty of Art and Design, Institut Teknologi Bandung under the Program Penelitian, Pengabdian kepada Masyarakat dan Inovasi 2021.

\section{REFERENCES}

[1] B. Titisari, M. Rigout, T. Cassidy, A. Dallabona, Designing an Appropriate Technology for Revitalising Traditional Craft Practice. Case study: Indonesian Stitch Resist Dyeing, in: The Design Journal, 22(sup1), 2019, pp. 1071-1086.

[2] B. Titisari, M. Rigout, T. Cassidy, A. Dallabona, Revitalisation strategies for Indonesian stitch resist dyeing practices, University of Leeds, 2020.

[3] A. Holroyd, Forging new futures: Cultural significance, revitalization, and authenticity, in: Design roots: Culturally significant designs, products, and practices, London, Bloomsbury Academic, 2018.

[4] T. Scrase, Precarious production: globalisation and artisan labour in the Third World, in: Third World Quarterly, 24(3), 2003, pp. 449-461.

[5] D. Chudasri, S. Walker, M. Evans, An overview of the issues facing the craft industry and the potential for design, with a case study in Upper Northern Thailand, in: DRS 2012 Bangkok Conference, Chulalongkorn University, Bangkok, 2012.

[6] A. Holroyd, T. Cassidy, M. Evans, E. Gifford, S. Walker, Design for 'Domestication': The decommercialisation of traditional crafts, in: 11th European Academy of Design Conference, Bolougne Billancourt, France, 2015.
[7] L. Chutia, M. Sarma, Commercialization of Traditional Crafts of South and South East Asia: A Conceptual Model based on Review of Literature, in: IIM Kozhikode Society \& Management Review, 5(2), 2016, pp. 107-119.

[8] A. Holroyd, T. Cassidy, M. Evans, S. Walker, Tradition: Revitalizing the Orkney Chair and Other Culturally Significant Crafts, in: Design and Culture, 9(3), 2017, pp. 283-299.

[9] UNESCO, Indonesian Batik, 2009. [Online]. Available: https://ich.unesco.org/. [Accessed 9 December 2018].

[10] PERMENDAGRI, Nomor 6: Perubahan Ketiga Atas Peraturan Menteri Dalam Negeri Nomor 60 Tahun 2007 Tentang Pakaian Dinas Pegawai Negeri Sipil di Lingkungan Departtemen Dalam Negeri dan Pemerintah Daerah, 2016. [Online]. Available: https://www.bphn.go.id/. [Accessed 2 May 2016].

[11] M. Hitchcock, Indonesian textiles, Singapore: Periplus Editions (HK) Ltd., 1991.

[12] S. Seman, Sasirangan: kain khas Banjar, Kalimantan Selatan: Lembaga Pengkajian dan Pelestarian Budaya Banjar, 2008.

[13] M. Hann, Patterns of culture - techniques of decoration and coloration, Leeds: University of Leeds, 2005.

[14] N. Juliana, Kajian Jumputan Pelangi Palembang, in: Jurnal Seni Rupa FBS UNIMED., vol. 7, no. 2, 2010. pp. 40-52.

[15] N. Belfer, Designing in batik and tie dye, Worcester USA: Davis Publications, 1972.

[16] J. Larsen, A. Bühler, G. Solyom, The dyer's art: ikat, batik, plangi, Van Nostrand Reinhold, 1976.

[17] C. Vezzoli, The "Material" Side of Design for Sustainability, in: Materials Experience: Fundamentals of Materials and Design, Elsevier Science \& Technology, 2013, pp. 107-121.

[18] E. Vink, K. Rabago, D. Glassner, P. Gruberb, Applications of life cycle assessment to NatureWorks(TM) polylactide (PLA) production, in: Polymer Degradation and Stability, vol. 80, 2003, p. 403-419.

[19] S. Madival, R. Auras, S. Singh, R. Narayan, Assessment of the environmental profile of PLA, PET and PS clamshell containers using 
LCA methodology, in: Journal of Cleaner Production, vol. 17, 2009, p. 1183-1194.

[20] P. Goswami, T. O'Haire, Developments in the use of green (biodegradable), recycled and biopolymer materials in technical nonwovens, in: Advances in Technical Nonwovens, Elsevier Ltd., 2016, pp. 97-114.

[21] S. Ahmad, A. Rasheed, Y. Nawab, Fibers for Technical Textiles, Springer Nature Switzerland AG, 2020.

[22] J. W. Slijkoord, 3D Printing Industry: Is Recycling PLA really better than composting?, 28 May 2015. [Online]. Available: https://3dprintingindustry.com/news/isrecycling-pla-really-better-than-composting49679/. [Accessed 21 August 2021]. 